\title{
GALEAZZI FRACTURES IN CHILDREN
}

\author{
H. P. J. WALSH, C. A. N. McLAREN, R. OWEN
}

From Alder Hey Children's Hospital, Liverpool

\begin{abstract}
We have reviewed 41 children under 15 years of age with a fracture of the radius and disruption of the inferior radio-ulnar joint. Despite the fact that the joint injury had not at first been recognised in $41 \%$ of cases and a variety of treatments had been used, the final results of conservative management were generally good. The more distal the radial fracture, the greater were the problems encountered.
\end{abstract}

Fracture of the shaft of the radius complicated by a dislocation of the inferior radio-ulnar joint (IRUJ) is a rare injury (Hughston 1957; Mikić 1975; Reckling 1982). It was originally described by Astley Cooper in 1826, and received its eponym from Riccardo Galeazzi of Milan in 1934, when he reported 18 cases to the Lombard Surgical Society. Many authors since then have noted its rarity in children (Hughston 1957; Reckling and Peltier 1965; Mikić 1975; King 1984), but few have specifically studied the incidence, diagnosis and clinical management in this age group.

Although the term Galeazzi fracture was originally applied to radial fractures occurring at the junction of the middle and distal thirds, the term has been used over the years to describe radial fractures at any level associated with disruption of the IRUJ. On this basis, we have included fracture-dislocations within the distal third of the radial shaft, but have excluded cases with fracture of the ulnar shaft, or injury affecting the distal radial or ulnar epiphysis.

\section{PATIENTS AND METHODS}

We reviewed the radiographs of 1453 patients aged 15 years or less who had presented with a diagnosis of fractured radius over a six-year period. In 41 cases there was unequivocal evidence of disruption of the IRUJ,

H. P. J. Walsh, FRCS, MCh Orth, Orthopaedic Registrar Alder Hey Children's Hospital, Eaton Road, Liverpool L12 2AP, England.

C. A. N. McLaren, FRCS, FRCS Ed, Orthopaedic Registrar Robert Jones and Agnes Hunt Hospital, Oswestry, Salop SY10 7AG, England.

R. Owen, FRCS, MCh Orth, Professor of Orthopaedic and Accident Surgery

Royal Liverpool Hospital, Prescott Street, PO Box 147, Liverpool L69 3BX. England.

Requests for reprints should be sent to Mr H. P. J. Walsh. (C) 1987 British Editorial Society of Bone and Joint Surgery $0301-620 \times / 87 / 5145 \$ 2.00$ either on a true lateral radiograph or from clinical notes written by the doctor at the time of injury. Of these patients, 30 were personally reviewed and the result in 11 was obtained from review of the case records, a questionnaire and the radiographs.

We recorded the age and sex of the patient, the side and mode of injury, whether or not the nature of the injury was recognised at first attendance, the position of the fracture in the radial shaft and the mode and outcome of treatment. It became evident that a much higher proportion of the radial fractures were within the distal third than that found in an adult population (Mikic 1975). We therefore grouped those with the fracture within the distal third of the radius (Figs 1 and 2) and those with the fracture at the junction of the middle and distal thirds (Figs 3 and 4). Because it was felt the mechanism of injury was different when the distal fragment was displaced anteriorly rather than posteriorly, the groups were further subdivided according to this, giving four categories of fracture-dislocation (Table I and Figs 1 to 4 ).

Table I. Level and displacement of the distal radial fragment in 41 Galeazzi fractures in children

\begin{tabular}{lll}
\hline & \multicolumn{2}{l}{ Level of radial fracture } \\
\cline { 2 - 3 } $\begin{array}{l}\text { Displacement } \\
\text { of radius }\end{array}$ & $\begin{array}{l}\text { Within distal } \\
\text { third }\end{array}$ & $\begin{array}{l}\text { At junction of } \\
\text { distal and } \\
\text { middle third }\end{array}$ \\
\hline Anterior & 8 & 13 \\
Posterior & 13 & 7 \\
\hline
\end{tabular}

The result of treatment was adjudged using Mikić's (1975) criteria. An excellent result had satisfactory union with near-perfect alignment and length, no subluxation, no limitation of function at the elbow or wrist and no limitation of supination or pronation. A fair result showed one or more of the following: delayed union, obvious subluxation of the ulnar head, limitation of pronation or supination of up to $45^{\circ}$ or other restriction of 


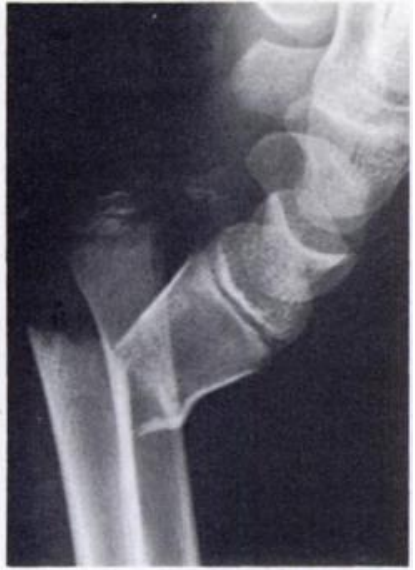

Fig. 1

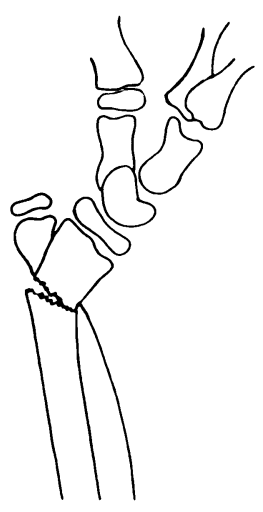

Fig. 2

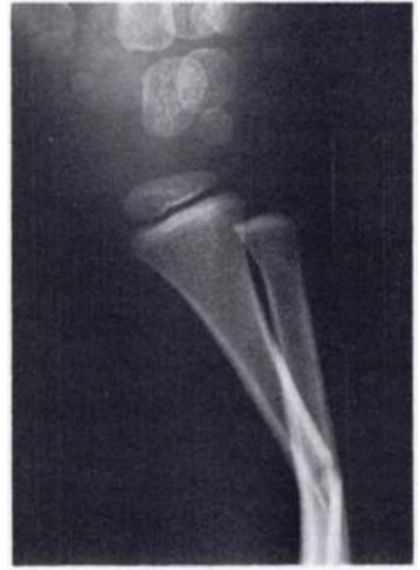

Fig. 3

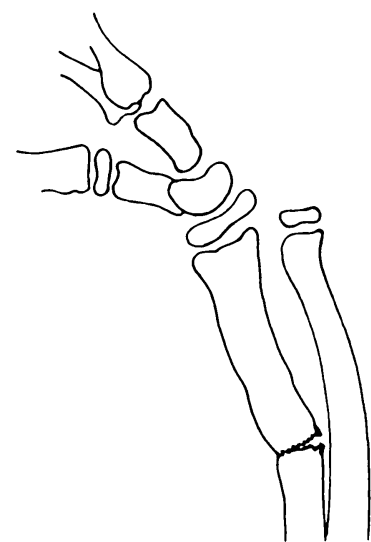

Fig. 4

Radiograph and diagram to show a fracture-dislocation within the distal third of the forearm with posterior displacement of the radius.

movement at elbow or wrist. A poor result was one with one or more of the following: patient dissatisfaction, pain, obvious deformity of the forearm, non-union, significant shortening of the radius, limitation of pronation or supination of more than $45^{\circ}$, or excessive restriction of elbow and wrist function.

Anteroposterior and true lateral radiographs were taken at the time of review. The final clinical and radiographic outcome was then correlated with the category of the fracture-dislocation, the initial recognition of the injury and, most importantly, with the mode of treatment.

\section{RESULTS}

The age distribution of the patients is shown in Figure 5 , the majority being from nine to 12 years of age, while 14 $(34 \%)$ were under 10 . There were 31 boys and 10 girls. Twenty-one patients had fallen from a height, while the others fell whilst running, playing football or rollerskating. In 17 patients injury was to the right wrist and in 24 to the left. In 17 cases $(41 \%)$, injury to the IRUJ was not at first recognised.

Of the 21 patients with a fracture within the distal third of the radius, $14(67 \%)$ had fallen from a height compared with only seven $(35 \%)$ of the 20 with a more proximal fracture.

Table II summarises the treatment which had been employed. In five of the 16 cases where a below-elbow plaster had been used, the injury to the IRUJ had been recognised. An acceptable initial reduction of the radius had been obtained in all except two cases. In these a closed reduction could not be achieved and open reduction with internal fixation was performed.

True lateral post-reduction radiographs had been taken in only 28 cases, so an accurate estimate of the frequency of full reduction of the IRUJ was not possible. Of the 28 cases with adequate films, four had inaccurate

Radiograph and diagram to show a classic Galeazzi injury with the radial fracture at the junction of the middle and distal thirds. There is anterior displacement of the distal radius.

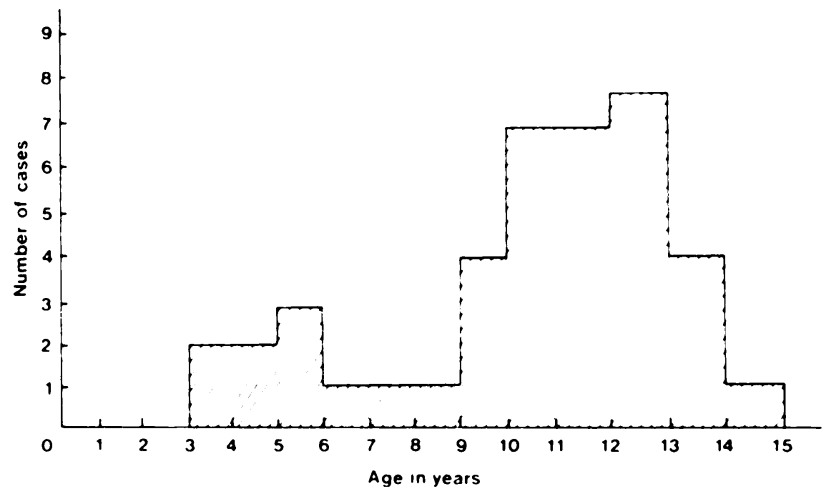

Fig. 5

The age distribution of 41 Galeazzi injuries in children.

reduction of the IRUJ ; in all four the original joint injury had been unrecognised.

The outcome of treatment was then correlated with the site of the fracture and the type of plaster immobilisation used, with results which are summarised in Table III. Excellent results were found in all patients with a posteriorly displaced distal radial fragment who were treated in the traditional manner by reduction and an above-elbow plaster in supination. This also applied to this type of case immobilised in neutral rotation. Reduction of the radius in these cases had resulted in automatic reduction of the IRUJ, even when the joint injury had not been initially recognised.

Table II. Treatment given in 41 Galeazzi fractures in children
Manipulation and below-elbow plaster

16 Manipulation and above-elbow plaster Supination Neutral Pronation $\begin{aligned} & \text { Internal } \\ & \text { fixation }\end{aligned}$
10

\section{7}


Table III. Result related to level of fracture and mode of treatment

\begin{tabular}{|c|c|c|c|c|c|c|}
\hline \multirow[b]{2}{*}{ Result } & \multirow[b]{2}{*}{ Number } & \multicolumn{2}{|c|}{ Level of fracture } & \multirow{2}{*}{$\begin{array}{l}\text { Treatment } \\
\begin{array}{l}\text { Below-elbow } \\
\text { plaster }\end{array}\end{array}$} & \multirow[b]{2}{*}{$\begin{array}{l}\text { Above-elbow } \\
\text { plaster }\end{array}$} & \multirow[b]{2}{*}{$\begin{array}{l}\text { Internal } \\
\text { fixation }\end{array}$} \\
\hline & & $\begin{array}{l}\text { Distal } \\
\text { third }\end{array}$ & $\begin{array}{l}\text { Junction of } \\
\text { distal and } \\
\text { middle third }\end{array}$ & & & \\
\hline Excellent & 25 & 10 & 15 & 7 & 17 & 1 \\
\hline Fair & 13 & 8 & 5 & 6 & 6 & 1 \\
\hline Poor & 3 & 3 & 0 & 3 & 0 & 0 \\
\hline Total & 41 & 21 & 20 & 16 & 23 & 2 \\
\hline
\end{tabular}

For those cases with anterior displacement of the distal end of the radius, treatment had varied considerably so that no firm conclusions could be drawn. The influence of the position of rotation in an above-elbow plaster on the result is summarised in Table IV.

Of the 17 cases in which there was initial failure to recognise the joint injury, seven had excellent results. Of the four who had inaccurate reduction of the IRUJ, three had only fair results with persistent subluxation and mild restriction of wrist movements and one had a poor outcome with pain and moderate restriction of movement.

In general, fractures within the distal third were associated with a worse outcome because of poorer recognition of the joint injury, a higher incidence of below-elbow immobilisation and possibly because there was more initial disruption.

\section{DISCUSSION}

Although many authors allude to the rarity of Galeazzi fracture-dislocations in children, none has given an incidence. Our study indicates that less than $5 \%$ of all radial shaft fractures in children are associated with obvious disruption of the IRUJ, though more may have a lesser degree of damage to the joint. Treatment, even in adults, is controversial (Hughston 1957; Mikić 1975; Reckling 1982) and internal fixation is frequently used.

Of the 41 cases in our series, 36 had excellent or fair results after simple manipulation and plaster immobilisation. The average healing time was 4 to 6 weeks and there were no cases of delayed union. Periosteal continuity probably accounts for the greater ease in restoring radial length and alignment in children, while the IRUJ often regains its original position with adequate stability. This stability depends on the local radio-ulnar ligaments, the pronator quadratus and, most importantly, the triangular interosseous fibrocartilage. It is likely that once position is restored and maintained, healing of this structure occurs more effectively and rapidly in children than in adults.

The cause of the classic Galeazzi injury is probably a fall on to the outstretched hand with extreme pronation of the forearm. In our series, of the 33 cases with classic
Table IV. Result in 23 cases treated in an above-elbow plaster related to the position of rotation of the forearm

\begin{tabular}{lccl} 
Result & Supination & Neutral & Pronation \\
\hline Excellent & 6 & 7 & 4 \\
Fair & 0 & 3 & 3 \\
Poor & 0 & 0 & 0
\end{tabular}

injuries or more distal fractures with posterior displacement, 21 gave such a history, the fall often being from a considerable height.

In those cases with a distal fracture and anterior displacement of the radius there was no such consistent history of the mechanism of injury and it seemed that different forces were involved. No patient had a history of a direct blow to the forearm but it appeared that distal fractures were associated with more severe trauma than the proximal injuries. Interestingly Moore, Lester and Sarmiento (1985) attributed their failure to reproduce Galeazzi fractures experimentally to their inability to provide forces of sufficient "velocity or magnitude".

The diagnosis of Galeazzi fracture-dislocation in children should not be difficult. First, the possibilities of such an injury should be remembered, especially when the child has fallen from a height. Secondly, every effort must be made to obtain true lateral radiographs of the wrist no matter how difficult this may seem; we do agree, however, that this is not always possible (Mino, Palmer and Levinsohn 1983). Thirdly, and perhaps most importantly, a careful clinical appraisal of the state of the IRUJ must be made before anaesthesia (not easy in the distal radial injuries) and also under anaesthesia before and after reduction of the fracture.

In the series we report, treatment was varied even when the type of injury was recognised. In a few cases, although good initial reduction of both the radius and the IRUJ was obtained, there was subsequent loss of position at the joint. This was due either to the ill-advised use of a below-elbow plaster or to the use of an inappropriate position in an above-elbow plaster. We would advise that once the radial fracture has been reduced, relocation of the joint should also be checked and then the forearm should be immobilised in an above- 
elbow plaster in such a position as to minimise redisplacement.

In choosing this position it is necessary to consider the main deforming forces acting on the distal fragment, namely the pronator quadratus and brachioradialis muscles. Thus, whether the fracture was originally angulated posteriorly or anteriorly, the forearm should be held supinated in the plaster to counteract these forces; our results substantiate this analysis. However, immobilisation in a neutral or pronated position can give satisfactory results provided that the IRUJ is reduced and stable at the time of immobilisation and an aboveelbow plaster is used to prevent subsequent rotation of the forearm.

We would like to thank Mr C. J. E. Monk and Mr J. C. Dorgan of Royal Liverpool Children's Hospital, Mr J. F. Taylor of Alder Hey Children's Hospital and Mr P. H. Corkery of Ysbyty Glan Clwyd for permitting us to review their patients for this study. We would also like to thank Mrs I. L. Giff for typing the paper.

\section{REFERENCES}

Cooper Sir A. A treatise on dislocations and on fractures of the joints. 5th ed. London: Longman, 1826.

Hughston JC. Fracture of the distal radial shaft: mistakes in management. J Bone Joint Surg [Am] 1957:39-A: 249-64.

King RE. Galeazzi fracture-dislocation. In : Rockwood CA Jr, Wilkins KE, King RE, eds. Fractures in children. Philadelphia etc: JB Lippincott Company, 1984:356 62.

Mikić ZD. Galeazzi fracture-dislocations. J Bone Joint Surg [Am] 1975:57-A:1071 80.

Mino DE, Palmer AK, Levinsohn EM. The role of radiography and computerised tomography in the diagnosis of subluxation and dislocation of the distal radioulnar joint. J Hand Surg 1983:8:23-31.

Moore TM, Lester DK, Sarmiento A. The stabilizing effect of softtissue constraints in artificial Galeazzi fractures. Clin Orthop 1985:194:189-94

Reckling FW. Unstable fracture-dislocations of the forearm (Monteggia and Galeazzi lesions). J Bone Surg [Am] 1982:64-A :857-63.

Reckling FW, Peltier LF. Riccardo Galeazzi and Galeazzi`s fracture. Surgery 1965;58:453-9. 